\title{
PRODAN-conjugated DNA: Synthesis and Photochemical Properties
}

Kazuki Tainaka, ${ }^{\dagger}$ Kazuo Tanaka, ${ }^{\dagger}$ Shuji Ikeda, ${ }^{\dagger}$ Ken-ichiro Nishiza, ${ }^{\ddagger}$ Tomo Unzai, ${ }^{\ddagger}$ Yoshimasa Fujiwara, ${ }^{*}$ Isao Saito ${ }^{\S}$ Akimitsu Okamoto ${ }^{*}, \dagger$

${ }^{\dagger}$ Frontier Research System, RIKEN (The Institute of Physical and Chemical Research), Wako, Saitama 351-1098, Japan, ${ }^{\ddagger}$ Department of Synthetic Chemistry and Biological Chemistry, Faculty of Engineering, Kyoto University, Kyoto

615-8510, Japan, ${ }^{\S}$ NEWCAT Institute, School of Engineering, Nihon University, and SORST, Japan Science and Technology Agency, Tamura, Koriyama 963-8642, Japan.

Phone, +81-48-467-9238; Fax, +81-48-467-9205; e-mail, aki-okamoto@riken.jp 
Synthetic protocols of ${ }^{\mathrm{PDN}} \mathrm{C},{ }^{\mathrm{PDN}} \mathrm{A}$, and ${ }^{\mathrm{PDN}} \mathrm{G}$

\section{5-[3-(6-Dimethylaminonaphthalen-2-yl)-3-hydroxy-1-propyn-1-yl]-3'O,5'O-bis(tert-butyldimethyls}

ilyl)-2'-deoxycytidine (7). To a solution of 5-iodo-3'O,5'O-bis(tert-butyldimethylsilyl)-2'-deoxycytidine $(1.0 \mathrm{~g}, 1.72 \mathrm{mmol}), 2(320 \mathrm{mg}, 1.42 \mathrm{mmol})$, and triethylamine $(780 \mu \mathrm{L}, 5.51 \mathrm{mmol})$ in DMF $(10 \mathrm{~mL})$ were added tetrakis(triphenylphosphine)palladium(0) (398 mg, $0.34 \mathrm{mmol})$ and copper(I) iodide (131 $\mathrm{mg}, 0.69 \mathrm{mmol}$ ) under nitrogen. The mixture was stirred at room temperature for $3 \mathrm{~h}$. The resulting mixture was concentrated in vacuo and diluted ethyl acetate. This solution was washed with $5 \%(w / v)$ EDTA solution and 5\% $(w / v)$ sodium bisulfite solution, dried over $\mathrm{Na}_{2} \mathrm{SO}_{4}$, filtered and evaporated. The crude product was purified by silica gel column chromatography (chloroform-methanol $=50-20: 1$ ) to yield 7 (890 mg, $1.31 \mathrm{mmol}, 92 \%)$ as a yellow solid; ${ }^{1} \mathrm{H} \mathrm{NMR}\left(\mathrm{CDCl}_{3}, 400 \mathrm{MHz}\right) \delta 8.06(\mathrm{~d}, 1 \mathrm{H}, J=5.1$ Hz), $7.77(\mathrm{~s}, 1 \mathrm{H}), 7.68(\mathrm{~d}, 1 \mathrm{H}, J=9.0 \mathrm{~Hz}), 7.65(\mathrm{~d}, 1 \mathrm{H}, J=8.4 \mathrm{~Hz}), 7.51(\mathrm{dd}, 1 \mathrm{H}, J=1.6,8.4 \mathrm{~Hz}), 7.16$ (dd, 1H, $J=2.6,9.2 \mathrm{~Hz}), 6.90$ (d, 1H, $J=2.4 \mathrm{~Hz}), 6.24$ (t, 1H, $J=6.2 \mathrm{~Hz}$ ), 5.93 (brs, $1 \mathrm{H}), 5.72(\mathrm{~d}, 1 \mathrm{H}, J$ $=4.0 \mathrm{~Hz}), 4.35-4.31(\mathrm{~m}, 1 \mathrm{H}), 3.94-3.91(\mathrm{~m}, 1 \mathrm{H}), 3.87(\mathrm{ddd}, 1 \mathrm{H}, J=2.7,6.4,11.5 \mathrm{~Hz}), 3.72(\mathrm{dt}, 1 \mathrm{H}, J=$ 2.0, $11.4 \mathrm{~Hz}), 3.05$ (s, 6H), 2.44 (ddd, 1H, $J=4.0,6.0,13.4 \mathrm{~Hz}), 2.04-1.96(\mathrm{~m}, 1 \mathrm{H}), 0.87$ (s, 9H), 0.81 (s, 9H), 0.05-0.00 (m, 12H); $\left.{ }^{13} \mathrm{C} \mathrm{NMR} \mathrm{(} \mathrm{CDCl}_{3}, 100 \mathrm{MHz}\right) \delta 164.4,154.3,149.0,143.91,143.86,134.9$, $133.76,133.73128 .9,127.0,126.31,126.30,125.21,125.15,124.70,124.67,116.77,116.74,106.32$, 106.26, 96.14, 96.11, 90.1, 88.03, 87.99, 86.76, 86.71, 77.5, 71.4, 65.2, 62.5, 42.5, 40.8, 25.9, 25.7, 18.3, 18.0, -4.6, -4.9, -5.40, -5.43, -5.6; FABMS (NBA/DMSO) $\mathrm{m} / \mathrm{z} 679\left([\mathrm{M}+\mathrm{H}]^{+}\right)$, HRMS calcd. for $\mathrm{C}_{36} \mathrm{H}_{55} \mathrm{O}_{5} \mathrm{~N}_{4} \mathrm{Si}_{2}\left([\mathrm{M}+\mathrm{H}]^{+}\right)$679.3706, found 679.3650.

\section{$4 N$-(N,N-Dimethylaminomethylidenyl)-5-[3-(6-dimethylaminonaphthalen-2-yl)-3-hydroxy-1-prop} yl]-3'O,5' $O$-bis(tert-butyldimethylsilyl)-2'-deoxycytidine (8). A mixture of 7 (1.68 g, $2.47 \mathrm{mmol})$ and $10 \% \mathrm{Pd} / \mathrm{C}(1.0 \mathrm{~g})$ in ethanol $(400 \mathrm{~mL})$ was stirred under hydrogen atmosphere at room temperature for 9 h. The mixture was filtered through celite, washed with methanol and evaporated under reduced pressure. The crude product was purified by silica gel chromatography (ethyl acetate-methanol = 
$50-10: 1$ ) to yield the corresponding reduction product (diastereomeric mixture, $1.35 \mathrm{~g}, 1.98 \mathrm{mmol}$, $80 \%)$ as a white solid; ${ }^{1} \mathrm{H} \mathrm{NMR}\left(\mathrm{CDCl}_{3}, 400 \mathrm{MHz}\right) \delta 7.64(\mathrm{dd}, 1 \mathrm{H}, J=2.2,9.2 \mathrm{~Hz}), 7.62-7.60(\mathrm{~m}, 2 \mathrm{H})$, 7.47 and $7.46(\mathrm{~s} \times 2$, total $1 \mathrm{H}), 7.32(\mathrm{~d}, 1 \mathrm{H}, J=8.6 \mathrm{~Hz}), 7.13(\mathrm{dd}, 1 \mathrm{H}, J=2.4,9.2 \mathrm{~Hz}), 6.89$ and 6.88 $(\mathrm{s} \times 2$, total $1 \mathrm{H}), 6.61(\mathrm{brs}, 2 \mathrm{H}), 6.28(\mathrm{t}, 1 \mathrm{H}, J=6.8 \mathrm{~Hz}), 4.79$ and $4.77(\mathrm{t} \times 2$, total $1 \mathrm{H}, J=2.9 \mathrm{~Hz}), 4.32$ and 4.30 (quartet×2, total $1 \mathrm{H}, J=3.2 \mathrm{~Hz}$ ), 3.87 (quartet, $1 \mathrm{H}, J=2.7 \mathrm{~Hz}$ ), $3.78(\mathrm{dd}, 1 \mathrm{H}, J=3.1,11.4 \mathrm{~Hz}$ ), $3.70(\mathrm{dt}, 1 \mathrm{H}, J=2.9,11.2 \mathrm{~Hz}), 3.02(\mathrm{~s}, 6 \mathrm{H}), 2.50-2.43(\mathrm{~m}, 2 \mathrm{H}), 2.38-2.31(\mathrm{~m}, 1 \mathrm{H}), 2.04-1.98(\mathrm{~m}, 1 \mathrm{H})$, 1.94-1.83 (m, 2H), $0.87(\mathrm{~d}, 9 \mathrm{H}, J=2.4 \mathrm{~Hz}), 0.84(\mathrm{~d}, 9 \mathrm{H}, J=5.7 \mathrm{~Hz}), 0.04(\mathrm{t}, 6 \mathrm{H}, J=3.3 \mathrm{~Hz}), 0.01(\mathrm{t}$, $6 \mathrm{H},(\mathrm{d}, 9 \mathrm{H}, J=5.3 \mathrm{~Hz}) ;{ }^{13} \mathrm{C} \mathrm{NMR}\left(\mathrm{CDCl}_{3}, 100 \mathrm{MHz}\right) \delta 165.2,165.0,155.7,148.7,138.29,138.25$, $137.7,134.6,128.7,126.69,126.67,126.50,126.49,124.19,124.15,116.7,106.4,106.0,87.5,85.82$, $85.79,73.0,72.8,71.9,71.8,62.8,62.7,41.9,40.8,38.4,38.2,25.9,25.7,23.8,23.7,18.33,18.31,18.0$, $-4.6,-4.9,-5.43,-5.46,-5.49 ;$ FABMS (NBA/PEG/DMSO) $m / z 683\left([\mathrm{M}+\mathrm{H}]^{+}\right)$, HRMS calcd. for $\mathrm{C}_{36} \mathrm{H}_{59} \mathrm{O}_{5} \mathrm{~N}_{4} \mathrm{Si}_{2}\left([\mathrm{M}+\mathrm{H}]^{+}\right) 683.4019$, found 683.4012.

To a solution of the previous reaction product $(4.06 \mathrm{~g}, 5.94 \mathrm{mmol})$ in DMF $(10 \mathrm{~mL})$ was added $N, N$-dimethylformamide dimethylacetal $(876 \mu \mathrm{L}, 6.54 \mathrm{mmol})$. The mixture was stirred at $60{ }^{\circ} \mathrm{C}$ for $3 \mathrm{~h}$. The resulting mixture was evaporated and purified by silica gel column chromatography (chloroform-methanol $=20: 1)$ to yield $8(3.54 \mathrm{~g}, 4.80 \mathrm{mmol}, 81 \%)$ as a yellow solid; ${ }^{1} \mathrm{H} \mathrm{NMR}\left(\mathrm{CDCl}_{3}\right.$, $400 \mathrm{MHz}) \delta 8.89(\mathrm{~s}, 1 \mathrm{H}), 7.77$ and $7.71(\mathrm{~s} \times 2$, total $1 \mathrm{H}), 7.66(\mathrm{dd}, 1 \mathrm{H}, J=2.0,9.0 \mathrm{~Hz}), 7.63-7.60(\mathrm{~m}$, 2H), 7.36-7.31 $(\mathrm{m}, 1 \mathrm{H}), 7.15$ and $7.14(\mathrm{dd} \times 2$, total $1 \mathrm{H}, J=1.1,9.0 \mathrm{~Hz}), 6.91$ and $6.90(\mathrm{~s} \times 2$, total $1 \mathrm{H})$, 6.42 and $6.39(\mathrm{t} \times 2$, total $1 \mathrm{H}, J=6.4 \mathrm{~Hz}), 4.64$ and $4.62(\mathrm{dd} \times 2$, total $1 \mathrm{H}, J=3.5,6.2 \mathrm{~Hz}), 4.41-4.35(\mathrm{~m}$, $1 \mathrm{H}), 3.96-3.84(\mathrm{~m}, 2 \mathrm{H}), 3.77$ and $3.74(\mathrm{t} \times 2$, total $1 \mathrm{H}, J=2.7 \mathrm{~Hz}), 3.183$ and $3.179(\mathrm{~s} \times 2$, total $3 \mathrm{H}), 3.16$ and $3.15(\mathrm{~s} \times 2$, total $3 \mathrm{H}), 3.028$ and $3.025(\mathrm{~s} \times 2$, total $6 \mathrm{H}), 2.53-2.43(\mathrm{~m}, 2 \mathrm{H}), 2.08-1.97(\mathrm{~m}, 2 \mathrm{H})$, $1.87-1.80(\mathrm{~m}, 1 \mathrm{H}), 0.89-0.87(\mathrm{~m}, 18 \mathrm{H}), 0.08-0.06(\mathrm{~m}, 12 \mathrm{H}) ;{ }^{13} \mathrm{C} \mathrm{NMR}\left(\mathrm{CDCl}_{3}, 100 \mathrm{MHz}\right) \delta 170.4$, $158.84,158.81,156.0,148.5,140.2,140.0,138.0,134.3,128.69,128.66,126.8,126.4,124.65,124.62$, 124.06, 124.00. 116.57, 116.55, 113.4, 113.0, 106.5, 87.8, 87.6, 86.4, 86.1, 71.8, 71.7, 71.4, 71.1, 62.8, 
62.7, 42.3, 42.2, 41.9, 41.8, 41.2, 40.95, 40.86, 35.72, 35.67, 25.94, 25.93, 25.8, 24.0, 23.7, 18.41, 18.37, 18.0, -4.6, -4.9, -5.4; FABMS (NBA/PEG/DMSO) m/z $737\left([\mathrm{M}]^{+}\right)$, HRMS calcd. for $\mathrm{C}_{39} \mathrm{H}_{63} \mathrm{O}_{5} \mathrm{~N}_{5} \mathrm{Si}_{2}$ $\left([\mathrm{M}]^{+}\right)$737.4368, found 737.4371 .

\section{N-( $N, N$-Dimethylaminomethylidenyl)-5-PRODAN-3'O,5'O-bis(tert-butyldimethylsilyl)-2'-deoxyc}

ytidine (9). To a solution of $8(1.64 \mathrm{~g}, 2.11 \mathrm{mmol})$ and molecular sieves (4 $\AA, 1.0 \mathrm{~g})$ in dichloromethane (20 mL) was added 4-methylmorpholine $N$-oxide $(371 \mathrm{mg}, 3.17 \mathrm{mmol})$ and tetrapropylammonium perruthenate $(148 \mathrm{mg}, 0.42 \mathrm{mmol})$ at $0{ }^{\circ} \mathrm{C}$, and the mixture was stirred at room temperature for $2 \mathrm{~h}$. After diluted with diethyl ether $(100 \mathrm{~mL})$, Florisil $(60-100 \mathrm{mesh}, 500 \mathrm{mg})$ was added to the solution and the resulting mixture was stirred at room temperature for $15 \mathrm{~min}$. The mixture was filtered through Celite, washed with diethyl ether and evaporated under reduced pressure. The crude product was purified by silica gel column chromatography (chloroform-methanol = 50:1) to yield $9(1.18 \mathrm{~g}, 1.52$ mmol, $72 \%)$ as a lemon yellow solid; ${ }^{1} \mathrm{H}$ NMR $\left(\mathrm{CDCl}_{3}, 400 \mathrm{MHz}\right) \delta 8.78(\mathrm{~s}, 1 \mathrm{H}), 8.29(\mathrm{~d}, 1 \mathrm{H}, J=1.6$ Hz), $7.92(\mathrm{dd}, 1 \mathrm{H}, J=1.8,8.6 \mathrm{~Hz}), 7.76(\mathrm{~d}, 1 \mathrm{H}, J=9.2 \mathrm{~Hz}), 7.73(\mathrm{~s}, 1 \mathrm{H}), 7.62(\mathrm{~d}, 1 \mathrm{H}, J=8.8 \mathrm{~Hz}), 7.16$ $(\mathrm{dd}, 1 \mathrm{H}, J=2.6,9.2 \mathrm{~Hz}), 6.86(\mathrm{~d}, 1 \mathrm{H}, J=2.4 \mathrm{~Hz}), 6.40(\mathrm{t}, 1 \mathrm{H}, J=6.6 \mathrm{~Hz}), 4.37(\mathrm{dt}, 1 \mathrm{H}, J=3.5,6.2 \mathrm{~Hz})$, $3.93(\mathrm{q}, 1 \mathrm{H}, J=3.3 \mathrm{~Hz}), 3.85(\mathrm{dd}, 1 \mathrm{H}, J=3.3,11.2 \mathrm{~Hz}), 3.78(\mathrm{dd}, 1 \mathrm{H}, J=3.3,11.4 \mathrm{~Hz}), 3.42-3.25(\mathrm{~m}$, 2H), 2.95-2.86 (m, 2H), $3.12(\mathrm{~s}, 3 \mathrm{H}), 3.10(\mathrm{~s}, 6 \mathrm{H}), 3.05(\mathrm{~s}, 3 \mathrm{H}), 2.43(\mathrm{ddd}, 1 \mathrm{H}, J=3.5,6.0,13.4 \mathrm{~Hz})$, 2.01-1.94 (m, 1H), $0.89(\mathrm{~s}, 9 \mathrm{H}), 0.88(\mathrm{~s}, 9 \mathrm{H}), 0.09(\mathrm{~s}, 6 \mathrm{H}), 0.06(\mathrm{~d}, 6 \mathrm{H}, J=1.1 \mathrm{~Hz}) ;{ }^{13} \mathrm{C} \mathrm{NMR}\left(\mathrm{CDCl}_{3}\right.$, $100 \mathrm{MHz}) \delta 199.2,170.4,157.9,156.2,150.2,139.1,137.6,130.6,129.7,126.1,125.1,124.6,116.3$, $113.4,105.3,87.7,86.1,71.9,62.9,41.9,41.1,40.4,38.6,35.1,25.9,25.8,24.1,18.4,18.0,-4.6,-4.9$, -5.3, -5.4; FABMS (NBA/PEG/DMSO) $\mathrm{m} / \mathrm{z} 736\left([\mathrm{M}+\mathrm{H}]^{+}\right)$, HRMS calcd. for $\mathrm{C}_{39} \mathrm{H}_{62} \mathrm{O}_{5} \mathrm{~N}_{5} \mathrm{Si}_{2}([\mathrm{M}+$ $\mathrm{H}]^{+}$) 736.4290, found 736.4295 .

4- $N$-Acetyl-5-PRODAN-2'-deoxycytidine (10). To a solution of 9 (1.45 g, $1.97 \mathrm{mmol})$ in methanol (40 $\mathrm{mL}$ ) was added $28 \%$ ammonia $(10 \mathrm{~mL})$ at $0{ }^{\circ} \mathrm{C}$, and the mixture was stirred at $50{ }^{\circ} \mathrm{C}$ for $2 \mathrm{~h}$. The resulting mixture was evaporated to yield crude product $(1.34 \mathrm{~g}, 1.97 \mathrm{mmol}$, quant.). To a solution of crude product in pyridine $(10 \mathrm{~mL})$ was added acetic acid anhydrous $(187 \mu \mathrm{L}, 1.97 \mathrm{mmol})$ at room 
temperature, and the mixture was stirred at $50{ }^{\circ} \mathrm{C}$ for $4 \mathrm{~h}$. The resulting mixture was diluted with sat. aq. $\mathrm{NH}_{4} \mathrm{Cl}$ at $0{ }^{\circ} \mathrm{C}$, extracted with ethyl acetate. The organic phase was washed with brine, dried over anhydrous $\mathrm{MgSO}_{4}$, filtered, and concentrated in vacuo. The crude product was purified by silica gel column chromatography (hexane-ethyl acetate $=2: 1)$ to yield the acetyl-protected deoxycytidine $(1.20$ $\mathrm{g}, 1.67 \mathrm{mmol}, 85 \%)$ as a lemon yellow solid; ${ }^{1} \mathrm{H}$ NMR $\left(\mathrm{CDCl}_{3}, 400 \mathrm{MHz}\right) \delta 13.1$ (brs, $\left.1 \mathrm{H}\right), 8.34(\mathrm{~s}, 1 \mathrm{H})$, $7.96(\mathrm{~s}, 1 \mathrm{H}), 7.78(\mathrm{~d}, 1 \mathrm{H}, J=8.8 \mathrm{~Hz}), 7.72(\mathrm{~s}, 1 \mathrm{H}), 7.63(\mathrm{~d}, 1 \mathrm{H}, J=8.8 \mathrm{~Hz}), 7.17$ (dd, $1 \mathrm{H}, J=2.4,9.3$ Hz), $6.87(\mathrm{~d}, 1 \mathrm{H}, J=2.4 \mathrm{~Hz}), 6.28(\mathrm{t}, 1 \mathrm{H}, J=6.3 \mathrm{~Hz}), 4.43-4.36(\mathrm{~m}, 1 \mathrm{H}), 3.99-3.95(\mathrm{~m}, 1 \mathrm{H}), 3.87-3.77$ (m, 2H), 3.42-3.27 (m, 2H), $3.11(\mathrm{~s}, 6 \mathrm{H}), 2.84(\mathrm{t}, 2 \mathrm{H}, J=6.8 \mathrm{~Hz}), 2.28(\mathrm{~s}, 3 \mathrm{H}), 2.02-1.96(\mathrm{~m}, 1 \mathrm{H}), 0.89$ (s, 18H), 0.11 (s, 6H), 0.08 (s, 6H); ${ }^{13} \mathrm{C} \mathrm{NMR}\left(\mathrm{CDCl}_{3}, 100 \mathrm{MHz}\right) \delta 199.2,150.2$, 138.2, 137.7, 130.7, $129.9,126.1,124.9,124.5,116.3,113.4,105.2,88.0,85.5,72.2,63.0,41.3,40.3,37.4,28.9,25.9,25.7$, 23.6, 18.4, 17.9, -4.7, -4.9, -5.4; FABMS (NBA/DMSO) $\mathrm{m} / \mathrm{z} 722\left([\mathrm{M}+\mathrm{H}]^{+}\right)$, HRMS calcd. for $\mathrm{C}_{38} \mathrm{H}_{58} \mathrm{O}_{6} \mathrm{~N}_{4} \mathrm{Si}_{2}\left([\mathrm{M}+\mathrm{H}]^{+}\right)$722.3895, found 722.4093 .

To a solution of the previous reaction product $(824 \mathrm{mg}, 1.14 \mathrm{mmol})$ in THF $(5 \mathrm{~mL})$ was added TBAF (1 M solution in THF, $2.51 \mathrm{~mL}, 2.51 \mathrm{mmol}$ ). The mixture was stirred at room temperature for $3 \mathrm{~h}$. The resulting mixture was evaporated and purified by silica gel column chromatography (chloroform-methanol $=20: 1)$ to yield $10(539 \mathrm{mg}, 1.09 \mathrm{mmol}, 96 \%)$ as a lemon yellow solid; ${ }^{1} \mathrm{H}$ NMR (DMSO-d 6 , $400 \mathrm{MHz}) \delta 9.93(\mathrm{brs}, 1 \mathrm{H}), 8.44(\mathrm{~s}, 1 \mathrm{H}), 8.30(\mathrm{~s}, 1 \mathrm{H}), 7.89(\mathrm{~d}, 1 \mathrm{H}, J=9.3 \mathrm{~Hz}), 7.83$ $(\mathrm{dd}, 1 \mathrm{H}, J=1.0,8.8 \mathrm{~Hz}), 7.67(\mathrm{~d}, 1 \mathrm{H}, J=8.8 \mathrm{~Hz}), 7.26(\mathrm{dd}, 1 \mathrm{H}, J=2.4,9.3 \mathrm{~Hz}), 6.93(\mathrm{~d}, 1 \mathrm{H}, J=2.4$ Hz), $6.12(\mathrm{t}, 1 \mathrm{H}, J=6.3 \mathrm{~Hz}), 5.25$ (brs, 1H), 5.14 (brs, 1H), 4.27-4.21 (m, 1H), 4.13-4.04 (m, 1H), 3.84 (quartet, $1 \mathrm{H}, J=3.4 \mathrm{~Hz}), 3.68-3.53(\mathrm{~m}, 2 \mathrm{H}), 3.37-3.27(\mathrm{~m}, 3 \mathrm{H}), 3.05(\mathrm{~s}, 6 \mathrm{H}), 2.76(\mathrm{t}, 1 \mathrm{H}, J=7.3 \mathrm{~Hz})$, $2.23(\mathrm{~s}, 3 \mathrm{H}), 2.09-2.03(\mathrm{~m}, 1 \mathrm{H}) ;{ }^{13} \mathrm{C}$ NMR (DMSO-d $\left.6,100 \mathrm{MHz}\right) \delta 198.1,150.2,137.2,130.6,130.0$, $129.6,129.0,126.0,125.9,125.5,124.5,123.9,123.7,123.5,116.4,104.7,87.8,85.2,79.2,69.8,60.9$, 48.6, 37.2, 22.1; FABMS (Glycerol/PEG/DMSO) m/z $495\left([\mathrm{M}+\mathrm{H}]^{+}\right)$, HRMS calcd. for $\mathrm{C}_{26} \mathrm{H}_{31} \mathrm{O}_{6} \mathrm{~N}_{4}$ $\left([\mathrm{M}+\mathrm{H}]^{+}\right)$495.2238, found 495.2236.

\section{4-N-Acetyl-5-PRODAN-5' O-(4,4'-dimethoxytrityl)-2'-deoxycytidine}


3'O-(2-cyanoethyl)- $N, N$-diisopropylphosphoramidite (11). To a solution of 10 (500 $\mathrm{mg}, 1.01 \mathrm{mmol})$

in pyridine $(5 \mathrm{~mL})$ was added 4,4'-dimethoxytrityl chloride $(411 \mathrm{mg}, 1.21 \mathrm{mmol})$. The mixture was stirred at room temperature for $3 \mathrm{~h}$. The resulting mixture was evaporated and purified by silica gel column chromatography (chloroform-methanol $=50: 1)$ to yield the tritylated deoxycytidine $(724 \mathrm{mg}$, $0.91 \mathrm{mmol}, 90 \%$ ) as a lemon yellow solid; ${ }^{1} \mathrm{H}$ NMR (DMSO-d $\left.6,400 \mathrm{MHz}\right) \delta 9.92(\mathrm{brs}, 1 \mathrm{H}), 8.26(\mathrm{~s}, 1 \mathrm{H})$, $7.89(\mathrm{~s}, 1 \mathrm{H}), 7.82(\mathrm{~d}, 1 \mathrm{H}, J=9.3 \mathrm{~Hz}), 7.69(\mathrm{~d}, 1 \mathrm{H}, J=8.3 \mathrm{~Hz}), 7.62(\mathrm{~d}, 1 \mathrm{H}, J=8.8 \mathrm{~Hz}), 7.35(\mathrm{~d}, 2 \mathrm{H}, J=$ $7.8 \mathrm{~Hz}), 7.26-7.21(\mathrm{~m}, 7 \mathrm{H}), 7.12(\mathrm{t}, 1 \mathrm{H}, J=7.8 \mathrm{~Hz}), 6.93(\mathrm{~d}, 1 \mathrm{H}, J=2.0 \mathrm{~Hz}), 6.81(\mathrm{~d}, 4 \mathrm{H}, J=8.8 \mathrm{~Hz})$, $6.16(\mathrm{t}, 1 \mathrm{H}, J=6.3 \mathrm{~Hz}), 5.32(\mathrm{~d}, 1 \mathrm{H}, J=4.9 \mathrm{~Hz}), 4.26-4.21(\mathrm{~m}, 1 \mathrm{H}), 3.96(\mathrm{dd}, 1 \mathrm{H}, J=4.4,7.8 \mathrm{~Hz})$, $3.632(\mathrm{~s}, 3 \mathrm{H}), 3.627(\mathrm{~s}, 3 \mathrm{H}), 3.25-3.21(\mathrm{~m}, 2 \mathrm{H}), 3.06(\mathrm{~s}, 6 \mathrm{H}), 2.64-2.52(\mathrm{~m}, 1 \mathrm{H}), 2.34-2.28(\mathrm{~m}, 1 \mathrm{H})$, $2.24(\mathrm{~s}, 3 \mathrm{H}), 2.20-2.13(\mathrm{~m}, 1 \mathrm{H}) ;{ }^{13} \mathrm{C}$ NMR (DMSO-d $\left.6,100 \mathrm{MHz}\right) \delta 197.7,158.1,150.1,144.6,137.2$, $135.4,135.2,130.6,129.8,129.70,129.65,129.5,127.8,127.6,126.7,125.8,124.4,123.8,116.4,113.2$, 104.7, 86.0, 85.8, 79.2, 70.3, 63.6, 54.9, 37.6, 21.9; FABMS (Glycerol/PEG/DMSO) m/z 797 ([M + $\left.\mathrm{H}]^{+}\right)$, HRMS calcd. for $\mathrm{C}_{47} \mathrm{H}_{49} \mathrm{O}_{8} \mathrm{~N}_{4}\left([\mathrm{M}+\mathrm{H}]^{+}\right)$797.3550, found 797.3555.

To a solution of the tritylated deoxycytidine (40 mg, $50.2 \mu \mathrm{mol})$ and tetrazole $(3.54 \mathrm{mg}, 50.2 \mu \mathrm{mol})$ in anhydrous acetonitrile $(500 \mu \mathrm{L})$ was added 2-cyanoethyl tetraisopropylphosphorodiamidite $(15.8 \mu \mathrm{L}$, $50.2 \mu \mathrm{mol})$ under nitrogen. The mixture was stirred at room temperature for $30 \mathrm{~min}$. The mixture was filtered and used with no further purification.

\section{8-[3-(6-Dimethylaminonaphthalen-2-yl)-3-hydroxy-1-propyn-1-yl]-3' O,5'O-bis(tert-butyldimethyls}

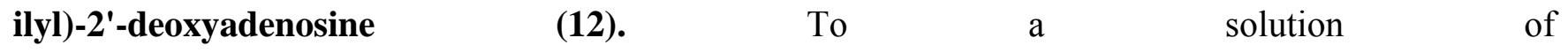
8-bromo-3'O,5'O-bis(tert-butyldimethylsilyl)-2'-deoxyadenosine (1.9 g, $3.4 \mathrm{mmol}), 2$ (700 mg, 3.1 mmol), and triethylamine $(1.43 \mathrm{~mL}, \quad 10 \mathrm{mmol})$ in DMF $(30 \mathrm{~mL})$ was added tetrakis(triphenylphosphine)palladium(0) $(718 \mathrm{mg}, 0.62 \mathrm{mmol})$ and copper(I) iodide (240 mg, 1.26 mmol) under nitrogen. The mixture was stirred at room temperature for $17 \mathrm{~h}$. The resulting mixture was concentrated in vacuo and diluted ethyl acetate. This solution was washed with $5 \%(w / v)$ EDTA solution and $5 \%(w / v)$ sodium bisulfite solution, dried over $\mathrm{Na}_{2} \mathrm{SO}_{4}$, filtered and evaporated. The crude product 
was purified by silica gel column chromatography (chloroform-methanol = $50: 1)$ to yield $12(1.33 \mathrm{~g}$, $1.89 \mathrm{mmol}, 61 \%)$ as a brown solid; ${ }^{1} \mathrm{H} \mathrm{NMR}\left(\mathrm{CDCl}_{3}, 400 \mathrm{MHz}\right) \delta 8.27(\mathrm{~s}, 1 \mathrm{H}), 7.90(\mathrm{~s}, 1 \mathrm{H}), 7.70(\mathrm{~d}, 1 \mathrm{H}$, $J=8.8 \mathrm{~Hz}), 7.66(\mathrm{dd}, 1 \mathrm{H}, J=2.0,8.8 \mathrm{~Hz}), 7.58(\mathrm{ddd}, 1 \mathrm{H}, J=1.6,5.6,8.4 \mathrm{~Hz}), 7.16(\mathrm{dd}, 1 \mathrm{H}, J=2.4$, $9.2 \mathrm{~Hz}), 6.89(\mathrm{~d}, 1 \mathrm{H}, J=2.8 \mathrm{~Hz}), 6.49(\mathrm{t}, 1 \mathrm{H}, J=6.4 \mathrm{~Hz}), 5.85(\mathrm{~d}, 1 \mathrm{H}, J=6.8 \mathrm{~Hz}), 5.82(\mathrm{brs}, 2 \mathrm{H}), 4.78$ (ddd, $1 \mathrm{H}, J=3.6,5.6,17.6 \mathrm{~Hz}), 3.97-3.86(\mathrm{~m}, 2 \mathrm{H}), 3.67$ (ddd, 1H, $J=2.4,4.8,10.4 \mathrm{~Hz}), 3.46$ (quintet, $1 \mathrm{H}, J=6.0 \mathrm{~Hz}), 3.05(\mathrm{~s}, 6 \mathrm{H}), 2.20(\mathrm{ddd}, 1 \mathrm{H}, J=4.0,6.8,17.2 \mathrm{~Hz}), 0.89$ (s, 9H), $0.83(\mathrm{~s}, 9 \mathrm{H}), 0.10-0.09$ $(\mathrm{m}, 6 \mathrm{H}),-0.01(\mathrm{~s}, 3 \mathrm{H}),-0.04(\mathrm{~s}, 3 \mathrm{H}) ;{ }^{13} \mathrm{C} \mathrm{NMR}\left(\mathrm{CDCl}_{3}, 100 \mathrm{MHz}\right) \delta 155.0,153.3,149.4,149.1,135.1$, $134.8,132.5,129.1,127.12,127.07,126.3,125.8,125.6,124.89,124.85,116.7,106.2,87.87,87.84$, 85.2, 72.6, 65.1, 65.0, 63.0, 40.8, 37.3, 18.4, 18.0, -4.7, -4.8, -5.4, -5.5; FABMS (NBA/CHCl $\left.{ }_{3}\right) \mathrm{m} / \mathrm{z}$ $702\left([\mathrm{M}+\mathrm{H}]^{+}\right), \mathrm{HRMS}$ calcd. for $\mathrm{C}_{37} \mathrm{H}_{54} \mathrm{O}_{4} \mathrm{~N}_{6} \mathrm{Si}_{2}\left([\mathrm{M}+\mathrm{H}]^{+}\right)$702.3745, found 702.3763 .

\section{N-(N,N-Dimethylaminomethylidenyl)-8-[3-(6-dimethylaminonaphthalen-2-yl)-3-hydroxy-1-prop}

yl]-3'O,5' O-bis(tert-butyldimethylsilyl)-2'-deoxyadenosine (13). A mixture of 12 (1.33 g, $1.89 \mathrm{mmol})$ and $5 \% \mathrm{Pd} / \mathrm{C}(1.5 \mathrm{~g})$ in methanol $(50 \mathrm{~mL})$ was stirred under hydrogen atmosphere at room temperature for 2 days. The mixture was filtered through Celite, washed with methanol and evaporated under reduced pressure. The crude product was purified by silica gel chromatography (chloroform-methanol = $50: 1$ ) to yield the corresponding reduction product (diastereomeric mixture, $604 \mathrm{mg}, 0.86 \mathrm{mmol}, 45 \%$ ) as a brown solid; ${ }^{1} \mathrm{H} \mathrm{NMR}\left(\mathrm{CDCl}_{3}, 400 \mathrm{MHz}\right) \delta 8.244$ and $8.241(\mathrm{~s} \times 2$, total $1 \mathrm{H}), 7.68-7.66(\mathrm{~m}, 2 \mathrm{H})$, 7.65 and $7.63(\mathrm{~s} \times 2$, total $1 \mathrm{H}), 7.37(\mathrm{dd}, 1 \mathrm{H}, J=1.6,8.4 \mathrm{~Hz}), 7.16(\mathrm{dd}, 1 \mathrm{H}, J=2.4,9.2 \mathrm{~Hz}), 6.91(\mathrm{~d}, 1 \mathrm{H}$, $J=2.4 \mathrm{~Hz}), 6.22$ and $6.18(\mathrm{t} \times 2$, total $1 \mathrm{H}, J=6.8 \mathrm{~Hz}), 5.57(\mathrm{brs}, 2 \mathrm{~h}), 4.98$ and $4.93(\mathrm{t} \times 2$, total $1 \mathrm{H}, J=6.0$ $\mathrm{Hz}), 4.78$ and $4.77(\mathrm{t} \times 2$, total $1 \mathrm{H}, J=3.6 \mathrm{~Hz}), 3.93-3.83(\mathrm{~m}, 2 \mathrm{H}), 3.67-3.54(\mathrm{~m}, 2 \mathrm{H}), 3.13-3.07(\mathrm{~m}$, 2H9, $3.04(\mathrm{~s}, 6 \mathrm{H}), 2.44-2.36(\mathrm{~m}, 2 \mathrm{H}), 2.19-2.11(\mathrm{~m}, 1 \mathrm{H}), 0.62(\mathrm{~d}, 9 \mathrm{H}, J=2.8 \mathrm{~Hz}), 0.81(\mathrm{~d}, 9 \mathrm{H}, J=4.8$ $\mathrm{Hz}), 0.12(\mathrm{~s}, 6 \mathrm{H}),-0.02--0.06(\mathrm{~m}, 6 \mathrm{H}) ; \mathrm{FABMS}\left(\mathrm{NBA} / \mathrm{CHCl}_{3}\right) \mathrm{m} / \mathrm{z} 707\left([\mathrm{M}+\mathrm{H}]^{+}\right), \mathrm{HRMS}$ calcd. for $\mathrm{C}_{37} \mathrm{H}_{58} \mathrm{O}_{4} \mathrm{~N}_{6} \mathrm{Si}_{2}\left([\mathrm{M}+\mathrm{H}]^{+}\right)$707.4136, found 707.4135.

To a solution of the previous reaction product $(604 \mathrm{mg}, 0.85 \mathrm{mmol})$ in DMF $(5 \mathrm{~mL})$ was added $N, N$-dimethylformamide dimethylacetal $(6.8 \mathrm{~mL}, 50 \mathrm{mmol})$. The mixture was stirred at room 
temperature for $6 \mathrm{~h}$. The resulting mixture was evaporated and purified by silica gel column chromatography (chloroform) to yield 13 (diastereomeric mixture, $483 \mathrm{mg}, 0.63 \mathrm{mmol}, 75 \%$ ) as a yellow solid; ${ }^{1} \mathrm{H}$ NMR $\left(\mathrm{CDCl}_{3}, 400 \mathrm{MHz}\right) \delta 8.89(\mathrm{~s}, 1 \mathrm{H}), 8.452$ and $8.450(\mathrm{~s} \times 2$, total $1 \mathrm{H}), 7.67-7.62(\mathrm{~m}$, 3H), $7.38(\mathrm{dt}, 1 \mathrm{H}, J=1.2,8.8 \mathrm{~Hz}), 7.15(\mathrm{dd}, 1 \mathrm{H}, J=2.4,9.2 \mathrm{~Hz}), 6.91(\mathrm{~d}, 1 \mathrm{H}, J=2.4 \mathrm{~Hz}), 6.28$ and $6.22(\mathrm{t} \times 2$, total $1 \mathrm{H}, J=6.8 \mathrm{~Hz}), 5.00-4.93(\mathrm{~m}, 1 \mathrm{H}), 4.80-4.75(\mathrm{~m}, 1 \mathrm{H}), 3.92-3.86(\mathrm{~m}, 2 \mathrm{H}), 3.68-3.65$ (m, $1 \mathrm{H}), 3.58$ and 3.55 (quintet $\times 2$, total $1 \mathrm{H}, J=6.8 \mathrm{~Hz}), 3.24(\mathrm{~s}, 3 \mathrm{H}), 3.19$ and $3.18(\mathrm{~s} \times 2$, total $3 \mathrm{H})$, $3.16-3.05(\mathrm{~m}, 2 \mathrm{H}), 3.03(\mathrm{~s}, 6 \mathrm{H}), 2.48-2.37(\mathrm{~m}, 2 \mathrm{H}), 2.16$ and $2.15(\mathrm{ddd} \times 2$, total $1 \mathrm{H}, J=4.0,6.4,12.0$ $\mathrm{Hz}), 1.44-1.33(\mathrm{~m}, 1 \mathrm{H}), 0.93$ and $0.92(\mathrm{~s} \times 2$, total $9 \mathrm{H}), 0.83$ and $0.82(\mathrm{~s} \times 2$, total $9 \mathrm{H}), 0.13$ and $0.12(\mathrm{~s} \times 2$, total $6 \mathrm{H}),-0.02$ and $-0.05(\mathrm{~d} \times 2$, total $6 \mathrm{H}, J=3.6 \mathrm{~Hz}) ;{ }^{13} \mathrm{C} \mathrm{NMR}\left(\mathrm{CDCl}_{3}, 100 \mathrm{MHz}\right) \delta 158.4,158.0$, $155.1,152.7,151.6,148.6,138.1,138.0,134.38,134.35,130.9,128.8,128.7,126.6,126.5,124.9,124.8$, $124.4,124.1,116.6,106.5,87.4,84.2,84.1,73.6,73.5,72.5,72.4,68.1,62.9,62.8,41.2,40.9,38.7$, $37.3,36.1,35.7,35.1,30.3,29.7,28.9,25.8,25.0,24.9,23.7,23.0,18.3,18.0,14.0,10.9,-4.7,-4.8$, $-5.4,-5.5 ;$ FABMS $\left(\mathrm{NBA} / \mathrm{CHCl}_{3}\right) \mathrm{m} / \mathrm{z} 762\left([\mathrm{M}+\mathrm{H}]^{+}\right)$, HRMS calcd. for $\mathrm{C}_{40} \mathrm{H}_{63} \mathrm{O}_{4} \mathrm{~N}_{7} \mathrm{Si}_{2}\left([\mathrm{M}+\mathrm{H}]^{+}\right)$ 762.4558 , found 762.4568 .

6N-( $N, N$-Dimethylaminomethylidenyl)-8-PRODAN-2'-deoxyadenosine (14). To a solution of 13 (116 mg, $0.15 \mathrm{mmol})$ and molecular sieves (4 $\AA, 75 \mathrm{mg})$ in dichloromethane (5 mL) was added 4-methylmorpholine $N$-oxide $(26 \mathrm{mg}, 0.23 \mathrm{mmol})$ and tetrapropylammonium perruthenate $(5 \mathrm{mg}, 0.014$ mmol) at $0{ }^{\circ} \mathrm{C}$, and the mixture was stirred at room temperature for $15 \mathrm{~h}$. After diluted with diethyl ether (50 mL), Florisil (60-100 mesh, $50 \mathrm{mg})$ was added to the solution and the resulting mixture was stirred at room temperature for $15 \mathrm{~min}$. The mixture was filtered through Celite, washed with diethyl ether and evaporated under reduced pressure. The crude product was purified by silica gel column chromatography (chloroform) to yield the PRODAN derivative (37 mg, $0.05 \mathrm{mmol}, 32 \%$ ) as a lemon yellow solid; ${ }^{1} \mathrm{H} \mathrm{NMR}\left(\mathrm{CDCl}_{3}, 400 \mathrm{MHz}\right) \delta 8.85(\mathrm{~s}, 1 \mathrm{H}), 8.45(\mathrm{~s}, 1 \mathrm{H}), 8.44(\mathrm{~d}, 1 \mathrm{H}, J=1.2 \mathrm{~Hz}), 7.98(\mathrm{dd}$, $1 \mathrm{H}, J=2.0,8.8 \mathrm{~Hz}), 7.80(\mathrm{~d}, 1 \mathrm{H}, J=8.8 \mathrm{~Hz}), 7.64(\mathrm{~d}, 1 \mathrm{H}, J=8.8 \mathrm{~Hz}), 7.17(\mathrm{dd}, 1 \mathrm{H}, J=2.4,9.2 \mathrm{~Hz})$, $6.87(\mathrm{~d}, 1 \mathrm{H}, J=2.4 \mathrm{~Hz}), 6.44(\mathrm{t}, 1 \mathrm{H}, J=7.2 \mathrm{~Hz}), 4.83(\mathrm{dt}, 1 \mathrm{H}, J=3.6,6.0 \mathrm{~Hz}), 3.97-3.62(\mathrm{~m}, 5 \mathrm{H})$, 
3.47-3.41 (m, 2H), 3.20 (s, 3H), 3.11 (s, 6H), 2.99 (s, 3H), 2.27 (ddd, 1H, J=4.0, 6.8, $13.2 \mathrm{~Hz}), 0.94$ (s, 9H), $0.82(\mathrm{~s}, 9 \mathrm{H}), 0.15(\mathrm{~d}, 6 \mathrm{H}, J=1.2 \mathrm{~Hz}),-0.03(\mathrm{~d}, 6 \mathrm{H}, J=15.2 \mathrm{~Hz}) ;{ }^{13} \mathrm{C} \mathrm{NMR}\left(\mathrm{CDCl}_{3}, 100 \mathrm{MHz}\right) \delta$ $197.8,158.1,154.5,152.96,151.4,150.3,137.7,130.7,130.3,130.1,126.2,125.3,125.1,124.5,116.3$, $105.3,87.5,84.1,72.5,62.9,41.0,40.4,37.4,35.5,35.1,25.9,22.7,18.3,18.1,-4.6,-4.7,-5.4,-5.5$; FABMS $\left(\mathrm{NBA} / \mathrm{CHCl}_{3}\right) \mathrm{m} / \mathrm{z} 760\left([\mathrm{M}+\mathrm{H}]^{+}\right)$, HRMS calcd. for $\mathrm{C}_{40} \mathrm{H}_{61} \mathrm{O}_{4} \mathrm{~N}_{7} \mathrm{Si}_{2}\left([\mathrm{M}+\mathrm{H}]^{+}\right) 760.4402$, found 760.4403 .

To a solution of the PRODAN derivative $(37 \mathrm{mg}, 0.05 \mathrm{mmol})$ in THF (500 $\mu \mathrm{L})$ was added TBAF $(1 \mathrm{M}$ solution in THF, $125 \mu \mathrm{L}, 0.13 \mathrm{mmol}$ ). The mixture was stirred at room temperature for $3 \mathrm{~h}$. The resulting mixture was evaporated and purified by silica gel column chromatography (chloroform-methanol $=50: 1)$ to yield $14(24 \mathrm{mg}, 0.045 \mathrm{mmol}, 92 \%)$ as a lemon yellow solid; ${ }^{1} \mathrm{H}$ NMR $\left(\mathrm{CDCl}_{3}, 400 \mathrm{MHz}\right) \delta 8.87(\mathrm{~s}, 1 \mathrm{H}), 8.44(\mathrm{~s}, 1 \mathrm{H}), 8.42(\mathrm{~d}, 1 \mathrm{H}, J=1.6 \mathrm{~Hz}), 7.95(\mathrm{dd}, 1 \mathrm{H}, J=1.6,8.8$ Hz), $7.79(\mathrm{~d}, 1 \mathrm{H}, J=9.2 \mathrm{~Hz}), 7.63(\mathrm{~d}, 1 \mathrm{H}, J=8.8 \mathrm{~Hz}), 7.16(\mathrm{dd}, 1 \mathrm{H}, J=2.4,7.6 \mathrm{~Hz}), 6.86(\mathrm{~d}, 1 \mathrm{H}, J=$ $2.8 \mathrm{~Hz}), 6.57(\mathrm{dd}, 1 \mathrm{H}, J=5.6,9.6 \mathrm{~Hz}), 4.84(\mathrm{dd}, 1 \mathrm{H}, J=4.4,5.2 \mathrm{~Hz}), 4.25(\mathrm{~s}, 1 \mathrm{H}), 4.01(\mathrm{dd}, 1 \mathrm{H}, J=1.6$, $12.8 \mathrm{~Hz}), 3.89-3.70(\mathrm{~m}, 4 \mathrm{H}), 3.41-3.25(\mathrm{~m}, 3 \mathrm{H}), 3.23(\mathrm{~s}, 3 \mathrm{H}), 3.11(\mathrm{~s}, 6 \mathrm{H}), 3.04(\mathrm{~s}, 3 \mathrm{H}), 2.37$ (dd, $1 \mathrm{H}, J$ $=6.8,13.2 \mathrm{~Hz}) ;{ }^{13} \mathrm{C} \mathrm{NMR}\left(\mathrm{CDCl}_{3}, 100 \mathrm{MHz}\right) \delta 197.5,159.0,158.3,153.2,151.8,151.0,150.3,137.8$, $130.8,130.2,130.0,126.2,125.0,124.4,116.3,105.2,89.5,86.3,73.8,63.6,41.2,40.4,35.5,35.2,24.1$, 22.4, 20.2, 19.7; FABMS (DTT/TG/CHCl $)$ m/z $532\left([\mathrm{M}+\mathrm{H}]^{+}\right)$, HRMS calcd. for $\mathrm{C}_{28} \mathrm{H}_{33} \mathrm{O}_{4} \mathrm{~N}_{7}([\mathrm{M}+$ $\mathrm{H}]^{+}$) 532.2672, found 532.2683.

\section{N-(N,N-Dimethylaminomethylidenyl)-8-PRODAN-5'O-(4,4'-dimethoxytrityl)-2'-deoxyadenosine} 3'O-(2-cyanoethyl)- $N, N$-diisopropylphosphoramidite (15). To a solution of 14 (49 $\mathrm{mg}, 0.092 \mathrm{mmol})$ in pyridine $(3 \mathrm{~mL})$ was added 4,4'-dimethoxytrityl chloride $(37 \mathrm{mg}, 0.11 \mathrm{mmol})$. The mixture was stirred at room temperature for $3 \mathrm{~h}$. The resulting mixture was evaporated and purified by silica gel column chromatography (chloroform-methanol $=50: 1)$ to yield the tritylated compound $(38 \mathrm{mg}, 0.046$ mmol, 49\%) as a lemon yellow solid; ${ }^{1} \mathrm{H} \mathrm{NMR}\left(\mathrm{CDCl}_{3}, 400 \mathrm{MHz}\right) \delta 8.82(\mathrm{~s}, 1 \mathrm{H}), 8.39(\mathrm{~d}, 1 \mathrm{H}, J=1.2$ Hz), $8.30(\mathrm{~s}, 1 \mathrm{H}), 7.93(\mathrm{dd}, 1 \mathrm{H}, J=2.0,8.8 \mathrm{~Hz}), 7.74(\mathrm{~d}, 1 \mathrm{H}, J=9.2 \mathrm{~Hz}), 7.60(\mathrm{~d}, 1 \mathrm{H}, J=8.4 \mathrm{~Hz}), 7.38$ 
$(\mathrm{d}, 2 \mathrm{H}, J=7.2 \mathrm{~Hz}), 7.27(\mathrm{~s}, 1 \mathrm{H}), 7.25(\mathrm{~s}, 1 \mathrm{H}), 7.20-7.10(\mathrm{~m}, 5 \mathrm{H}), 6.83(\mathrm{~d}, 1 \mathrm{H}, J=2.8 \mathrm{~Hz}), 6.74-6.71$

$(\mathrm{m}, 4 \mathrm{H}), 6.49(\mathrm{t}, 1 \mathrm{H}, J=5.6 \mathrm{~Hz}), 4.93-4.89(\mathrm{~m}, 1 \mathrm{H}), 4.11(\mathrm{~d}, 1 \mathrm{H}, J=4.4 \mathrm{~Hz}), 3.77-3.73(\mathrm{~m}, 2 \mathrm{H}), 3.702$ (s, 3H), $3.698(\mathrm{~s}, 3 \mathrm{H}), 3.66-3.56(\mathrm{~m}, 1 \mathrm{H}), 3.45-3.37(\mathrm{~m}, 4 \mathrm{H}), 3.17(\mathrm{~s}, 3 \mathrm{H}), 3.08(\mathrm{~s}, 6 \mathrm{H}), 2.95(\mathrm{~s}, 3 \mathrm{H})$, $2.38(\mathrm{ddd}, 1 \mathrm{H}, J=4.4,7.2,13.6 \mathrm{~Hz})$; FABMS $\left(\mathrm{NBA} / \mathrm{CHCl}_{3}\right) \mathrm{m} / \mathrm{z} 834\left([\mathrm{M}+\mathrm{H}]^{+}\right)$, HRMS calcd. for $\mathrm{C}_{49} \mathrm{H}_{51} \mathrm{O}_{6} \mathrm{~N}_{7}\left([\mathrm{M}+\mathrm{H}]^{+}\right)$834.3979, found 834.3984.

To a solution of the tritylated nucleoside $(37 \mathrm{mg}, 40 \mu \mathrm{mol})$ and tetrazole $(3.1 \mathrm{mg}, 44 \mu \mathrm{mol})$ in anhydrous acetonitrile $(400 \mu \mathrm{L})$ was added 2-cyanoethyl tetraisopropylphosphorodiamidite (15 $\mu \mathrm{L}, 48$ $\mu \mathrm{mol})$ under nitrogen. The mixture was stirred at room temperature for $30 \mathrm{~min}$. The mixture was filtered and used with no further purification.

\section{8-[3-(6-Dimethylaminonaphthalen-2-yl)-3-hydroxy-1-propyn-1-yl]-3' O,5'O-bis(tert-butyldimethyls}

$\begin{array}{llllll}\text { ilyl)-2'-deoxyguanosine } & \text { (16). } & \text { To } & \text { a } & \text { solution } & \text { of }\end{array}$

8-bromo-3'O,5'O-bis(tert-butyldimethylsilyl)-2'-deoxyguanosine (3.7 g, $6.5 \mathrm{mmol}), 2$ (1.1 g, $5.0 \mathrm{mmol})$, and triethylamine $(2.3 \mathrm{~mL}, \quad 16.5 \mathrm{mmol})$ in $\mathrm{DMF} \quad(20 \mathrm{~mL})$ was added tetrakis(triphenylphosphine)palladium(0) (1.2 g, $1.0 \mathrm{mmol})$ and copper(I) iodide (380 $\mathrm{mg}, 2.0 \mathrm{mmol})$ under nitrogen. The mixture was stirred at $60{ }^{\circ} \mathrm{C}$ for $1 \mathrm{~h}$. The resulting mixture was concentrated in vacuo and diluted ethyl acetate. This solution was washed with 5\% (w/v) EDTA solution and 5\% (w/v) sodium bisulfite solution, dried over $\mathrm{Na}_{2} \mathrm{SO}_{4}$, filtered and evaporated. The crude product was purified by silica gel column chromatography (chloroform-methanol = $30: 1)$ to yield $16(3.4 \mathrm{~g}, 4.7 \mathrm{mmol}, 93 \%)$ as an orange solid; ${ }^{1} \mathrm{H} \mathrm{NMR}\left(\mathrm{CDCl}_{3}, 400 \mathrm{MHz}\right) \delta 11.76(\mathrm{brs}, 1 \mathrm{H}) 7.87$ and $7.83(\mathrm{~s} \times 2$, total $1 \mathrm{H})$, 7.68-7.61 (m, 2H), $7.55(\mathrm{~d}, 1 \mathrm{H}, J=8.8 \mathrm{~Hz}), 7.13$ and $7.11(\mathrm{dd} \times 2$, total $1 \mathrm{H}, J=2.4,7.3 \mathrm{~Hz}), 6.89$ and $6.87(\mathrm{~d} \times 2$, total $1 \mathrm{H}, J=2.4 \mathrm{~Hz}), 6.33(\mathrm{t}, 1 \mathrm{H}, J=6.8 \mathrm{~Hz}), 6.24(\mathrm{brs}, 2 \mathrm{H}), 5.80$ and $5.77(\mathrm{~s} \times 2$, total $1 \mathrm{H})$, 4.58-4.54 (m, 1H), 3.92-3.87 (m, 1H), 3.78-3.73 (m, 1H), 3.68-3.62 (m, 1H),3.30-3.25 (m, 1H), 3.03 and $3.01(\mathrm{~s} \times 2$, total $6 \mathrm{H}), 2.17-2.07(\mathrm{~m}, 1 \mathrm{H}), 0.87-0.82(\mathrm{~m}, 18 \mathrm{H}), 0.09--0.04(\mathrm{~m}, 12 \mathrm{H}) ;{ }^{13} \mathrm{C}$ NMR $\left(\mathrm{CDCl}_{3}, 100 \mathrm{MHz}\right) \delta 158.1,153.6,151.13,151.09,148.8,134.7,134.3,133.0,131.3,131.1,129.0$, $128.3,126.8,126.34,126.28,125.44,125.38,124.95,124.90,117.5,117.4,116.7,116.6,106.37$, 
$106.32,95.7,87.55,87.48,84.5,75.52,75.42,72.64,72.57,64.77,64.61,63.2,40.78,40.75,37.0$, 25.84, 25.73, 18.3, 17.9, -4.7, -4.8, -5.37, -5.40; FABMS (NBA/CHCl $)_{3} \mathrm{~m} / \mathrm{z} 718\left([\mathrm{M}+\mathrm{H}]^{+}\right), \mathrm{HRMS}$ calcd. for $\mathrm{C}_{37} \mathrm{H}_{54} \mathrm{~N}_{6} \mathrm{O}_{5} \mathrm{Si}_{2}\left([\mathrm{M}+\mathrm{H}]^{+}\right)$718.3694, found 718.3699.

\section{N-(N,N-Dimethylaminomethylidenyl)-8-[3-(6-dimethylaminonaphthalen-2-yl)-3-hydroxy-1-prop}

yl]-3'O,5' O-bis(tert-butyldimethylsilyl)-2'-deoxyguanosine (17). To a solution of 16 (603 $\mathrm{mg}, 0.84$ $\mathrm{mmol})$ and $\mathrm{PtO}_{2}(150 \mathrm{mg})$ in methanol was stirred under hydrogen atmosphere at room temperature for $12 \mathrm{~h}$. The mixture was filtered through Celite and washed methanol, and the filtrate and washings were combined and evaporated under reduced pressure. The crude product was purified by silica gel chromatography (chloroform-methanol $=50: 1)$ to yield the corresponding reduction product $(411 \mathrm{mg}$, $0.57 \mathrm{mmol}, 68 \%)$ as an orange solid; ${ }^{1} \mathrm{H} \mathrm{NMR}\left(\mathrm{CDCl}_{3}, 400 \mathrm{MHz}\right) \delta 11.82(\mathrm{brs}, 1 \mathrm{H}) 7.63-7.59(\mathrm{~m}, 3 \mathrm{H})$, $7.36(\mathrm{dd}, 1 \mathrm{H}, J=3.2,8.5 \mathrm{~Hz}), 7.11(\mathrm{dt}, 1 \mathrm{H}, J=2.8,8.8 \mathrm{~Hz}), 6.89(\mathrm{~d}, 1 \mathrm{H}, J=2.0 \mathrm{~Hz}), 6.20(\mathrm{brs}, 1 \mathrm{H})$, $6.05(\mathrm{dt}, 1 \mathrm{H}, J=6.8,14.2 \mathrm{~Hz}), 4.92(\mathrm{dt}, 1 \mathrm{H}, J=5.6,15.1 \mathrm{~Hz}), 4.60-4.52(\mathrm{~m}, 1 \mathrm{H}), 3.83-3.61(\mathrm{~m}, 3 \mathrm{H})$, 3.23-3.17 (m, 1H), $3.01(\mathrm{~s}, 6 \mathrm{H}), 2.99-2.90(\mathrm{~m}, 2 \mathrm{H}), 2.38-2.28(\mathrm{~m}, 2 \mathrm{H}), 2.06-2.01(\mathrm{~m}, 1 \mathrm{H}), 0.92-0.83$ $(\mathrm{m}, 18 \mathrm{H}), 0.095--0.040(\mathrm{~m}, 12 \mathrm{H}) ;{ }^{13} \mathrm{C} \mathrm{NMR}\left(\mathrm{CDCl}_{3}, 100 \mathrm{MHz}\right) \delta 158.4,152.7,152.39,152.34,150.3$, $148.4,137.98,137.93,134.2,128.6,126.8,126.5,126.4,124.4,124.14,124.08,116.5,115.7,106.49$, $106.44,87.1,83.68,83.63,73.0,72.18,72.10,62.7,40.9,40.7,37.2,36.1,25.89,25.86,25.78,25.73$, 25.75, 25.70, 24.5, 18.2, 17.9, -4.7, -4.8, -5.5; FABMS $\left(\mathrm{NBA} / \mathrm{CHCl}_{3}\right) \mathrm{m} / \mathrm{z} 723\left([\mathrm{M}+\mathrm{H}]^{+}\right), \mathrm{HRMS}$ calcd. for $\mathrm{C}_{37} \mathrm{H}_{58} \mathrm{O}_{5} \mathrm{~N}_{6} \mathrm{Si}_{2}\left([\mathrm{M}+\mathrm{H}]^{+}\right)$723.4086, found 723.4085 .

To a solution of the previous reaction product $(619 \mathrm{mg}, 0.86 \mathrm{mmol})$ in $\mathrm{DMF}(6 \mathrm{~mL})$ was added $N, N$-dimethylformamide dimethylacetal $(126 \mu \mathrm{L}, 0.86 \mathrm{mmol})$ and the mixture was stirred at $60{ }^{\circ} \mathrm{C}$ for 1 h. After evaporation of the solvent, the residue was purified by silica gel chromatography (chloroform-methanol $=50: 1)$ to yield $17\left(507 \mathrm{mg}, 0.65 \mathrm{mmol}, 76 \%\right.$ ) as an orange solid; ${ }^{1} \mathrm{H}$ NMR $\left(\mathrm{CDCl}_{3}, 400 \mathrm{MHz}\right) \delta 8.82(\mathrm{brs}, 1 \mathrm{H}), 8.51$ and $8.50(\mathrm{~s} \times 2$, total $1 \mathrm{H}), 7.68-7.61(\mathrm{~m}, 3 \mathrm{H}), 7.39$ and 7.37 $(\mathrm{dd} \times 2$, total $1 \mathrm{H}, J=2.2,3.8 \mathrm{~Hz}), 7.16$ and $7.14(\mathrm{~d} \times 2$, total $1 \mathrm{H}, J=2.4 \mathrm{~Hz}), 6.92$ and $6.91(\mathrm{~s} \times 2$, total $1 \mathrm{H})$, $6.29(\mathrm{t}, 1 \mathrm{H}, J=7.3 \mathrm{~Hz}), 4.97-4.92(\mathrm{~m}, 1 \mathrm{H}), 4.52$ and 4.49 (quintet $\times 2$, total $1 \mathrm{H}, J=3.4 \mathrm{~Hz}), 3.89-3.85$ 
$(\mathrm{m}, 1 \mathrm{H}), 3.74(\mathrm{~d}, 1 \mathrm{H}, J=5.9 \mathrm{~Hz}), 3.71(\mathrm{~d}, 1 \mathrm{H}, J=5.4 \mathrm{~Hz}), 3.16(\mathrm{~s}, 3 \mathrm{H}), 3.10(\mathrm{~s}, 3 \mathrm{H}), 3.03(\mathrm{~s}, 6 \mathrm{H})$, 3.01-2.91 (m, 2H), 2.49-2.32 (m, 2H), 2.11 and $2.08(\mathrm{ddd} \times 2$, total $1 \mathrm{H}, J=2.9,6.8,13.2 \mathrm{~Hz}), 0.91(\mathrm{~d}$, $9 \mathrm{H}, J=2.0 \mathrm{~Hz}), 0.87(\mathrm{~d}, 9 \mathrm{H}, J=5.9 \mathrm{~Hz}), 0.08(\mathrm{dd}, 6 \mathrm{H}, J=2.05 .9 \mathrm{~Hz}), 0.02(\mathrm{t}, 6 \mathrm{H}, J=8.3 \mathrm{~Hz}) ;{ }^{13} \mathrm{C}$ $\operatorname{NMR}\left(\mathrm{CDCl}_{3}, 100 \mathrm{MHz}\right) \delta 157.8,157.4,155.7,150.9,150.6,150.5,148.3,138.2,134.1,128.6,126.6$, $126.2,124.50,124.47,123.96,123.93,118.81,118.78,116.4,106.5,86.9,83.2,73.07,72.94,72.0,62.8$, $41.2,40.8,38.2,38.1,35.75,35.65,35.0,25.7,25.6,24.9,24.8,18.2,17.8,-4.7,-4.9,-5.5,-5.6$; FABMS (NBA/CHCl $\left.{ }_{3}\right) \mathrm{m} / \mathrm{z} 777\left([\mathrm{M}+\mathrm{H}]^{+}\right)$, HRMS calcd. for $\mathrm{C}_{40} \mathrm{H}_{63} \mathrm{O}_{5} \mathrm{~N}_{7} \mathrm{Si}_{2}\left([\mathrm{M}+\mathrm{H}]^{+}\right)$777.4429, found 777.4438 .

2N-(N,N-Dimethylaminomethylidenyl)-8-PRODAN-2'-deoxyguanosine (18). To a solution of 17 (1.64 g, $2.11 \mathrm{mmol})$ and molecular sieves (4 $\AA, 1.0 \mathrm{~g})$ in dichloromethane $(20 \mathrm{~mL})$ was added 4-methylmorpholine $\mathrm{N}$-oxide $(371 \mathrm{mg}, 3.17 \mathrm{mmol})$ and tetrapropylammonium perruthenate $(148 \mathrm{mg}$, $0.42 \mathrm{mmol}$ ) at $0{ }^{\circ} \mathrm{C}$, and the mixture was stirred at room temperature for $2 \mathrm{~h}$. After diluted with diethyl ether (1 L), Florisil (60-100 mesh, $250 \mathrm{mg}$ ) was added to the solution and the resulting mixture was stirred at room temperature for $15 \mathrm{~min}$. The mixture was filtered through Celite, washed with diethyl ether and evaporated under reduced pressure. The crude product was purified by silica gel column chromatography (chloroform-methanol $=50: 1)$ to yield the PRODAN nucleoside $(1.18 \mathrm{~g}, 1.52 \mathrm{mmol}$, $72 \%$ ) as a lemon yellow solid; ${ }^{1} \mathrm{H} \mathrm{NMR}\left(\mathrm{CDCl}_{3}, 400 \mathrm{MHz}\right) \delta 8.55(\mathrm{~s}, 1 \mathrm{H}), 8.45(\mathrm{~s}, 1 \mathrm{H}), 8.44(\mathrm{~d}, 1 \mathrm{H}, J$ $=1.2 \mathrm{~Hz}), 7.98(\mathrm{dd}, 1 \mathrm{H}), 7.70(\mathrm{~d}, 1 \mathrm{H}, J=8.8 \mathrm{~Hz}), 7.64(\mathrm{~d}, 1 \mathrm{H}, J=8.8 \mathrm{~Hz}), 7.17(\mathrm{dd}, 1 \mathrm{H}, J=2.4,9.2$ $\mathrm{Hz}), 6.87(\mathrm{~d}, 1 \mathrm{H}, J=2.4 \mathrm{~Hz}), 6.44(\mathrm{t}, 1 \mathrm{H}, J=7.2 \mathrm{~Hz}), 4.63$ (quin., 1H, $J=2.4 \mathrm{~Hz}$ ), 3.62-3.97 (m, 5H), 3.32-3.26 (m, 2H), $3.20(\mathrm{~s}, 3 \mathrm{H}), 3.11(\mathrm{~s}, 6 \mathrm{H}), 2.99(\mathrm{~s}, 3 \mathrm{H}), 2.27(\mathrm{~m}, 1 \mathrm{H}), 0.94(\mathrm{~s}, 9 \mathrm{H}), 0.82(\mathrm{~s}, 9 \mathrm{H}), 0.15$ $(\mathrm{d}, 6 \mathrm{H}, J=1.2 \mathrm{~Hz}), 0.03(\mathrm{~d}, 6 \mathrm{H}, J=15.2 \mathrm{~Hz}) ;{ }^{13} \mathrm{C} \mathrm{NMR}\left(\mathrm{CDCl}_{3}, 100 \mathrm{MHz}\right) \delta 199.1,158.2,157.3$, $156.9,156.1,150.7,148.7,134.9,130.8,130.7,129.7,128.7,127.2,124.9,118.9,117.3,107.5,92.3$, $72.0,66.1,61.3,43.9,42.1,40.3,40.2,39.7,39.6,25.92,25.90,25.88,25.85,25.84,25.81,18.4,18.1$, $17.8,-5.4,-5.5,-5.6,-5.7$; FABMS $\left(\mathrm{NBA} / \mathrm{CHCl}_{3}\right) \mathrm{m} / \mathrm{z} 775\left([\mathrm{M}+\mathrm{H}]^{+}\right)$, HRMS calcd. for $\mathrm{C}_{40} \mathrm{H}_{61} \mathrm{O}_{5} \mathrm{~N}_{7} \mathrm{Si}_{2}\left([\mathrm{M}+\mathrm{H}]^{+}\right)$775.4273, found 775.4277. 
To a solution of the PRODAN nucleoside $(964 \mathrm{mg}, 1.24 \mathrm{mmol})$ in THF $(20 \mathrm{~mL})$ was added TBAF (1 M solution in THF, $2.73 \mathrm{~mL}, 2.73 \mathrm{mmol}$ ). The mixture was stirred at room temperature for $2 \mathrm{~h}$. The resulting mixture was evaporated and purified by silica gel column chromatography (chloroform-methanol $=50: 1)$ to yield $18(636 \mathrm{mg}, 1.16 \mathrm{mmol}, 94 \%)$ as a lemon yellow solid; ${ }^{1} \mathrm{H}$ NMR (DMSO-d 6 , $400 \mathrm{MHz}) \delta 11.3(\mathrm{brs}, 1 \mathrm{H}), 8.52(\mathrm{~s}, 1 \mathrm{H}), 8.47(\mathrm{~s}, 1 \mathrm{H}), 7.95(\mathrm{~d}, 1 \mathrm{H}, J=9.3 \mathrm{~Hz}), 7.85$ $(\mathrm{d}, 1 \mathrm{H}, J=8.8 \mathrm{~Hz}), 7.69(\mathrm{~d}, 1 \mathrm{H}, J=8.8 \mathrm{~Hz}), 7.27(\mathrm{dd}, 1 \mathrm{H}, J=2.4,9.3 \mathrm{~Hz}), 6.95(\mathrm{~s}, 1 \mathrm{H}), 6.31(\mathrm{t}, 1 \mathrm{H}, J=$ $7.3 \mathrm{~Hz}), 5.32(\mathrm{~d}, 1 \mathrm{H}, J=4.4 \mathrm{~Hz}), 4.90(\mathrm{t}, 1 \mathrm{H}, J=5.9 \mathrm{~Hz}), 4.44(\mathrm{dt}, 1 \mathrm{H}, J=3.9,10.7 \mathrm{~Hz}), 3.85-3.81(\mathrm{~m}$, 1H), 3.70-3.51 (m, 4H), 3.35-3.31 (m, 1H), 3.19-3.14 (m, 2H), $3.11(\mathrm{~s}, 3 \mathrm{H}), 3.06(\mathrm{~s}, 6 \mathrm{H}), 3.01(\mathrm{~s}, 3 \mathrm{H})$, $2.19(\mathrm{ddd}, 1 \mathrm{H}, J=2.9,6.4,12.7 \mathrm{~Hz}) ;{ }^{13} \mathrm{C}$ NMR (DMSO-d $\left.6,100 \mathrm{MHz}\right) \delta 197.4,157.9,157.2,156.6$, $150.5,148.7,137.4,130.7,130.0,129.6,126.0,124.5,123.9,118.6,116.5,104.8,87.5,83.3,71.0,62.0$, 40.7, 39.9, 37.9, 34.6, 34.5, 22.0; FABMS (DTT/TG/CHCl $\left.{ }_{3}\right) \mathrm{m} / \mathrm{z} 548\left([\mathrm{M}+\mathrm{H}]^{+}\right)$, HRMS calcd. for $\mathrm{C}_{28} \mathrm{H}_{33} \mathrm{O}_{5} \mathrm{~N}_{7}\left([\mathrm{M}+\mathrm{H}]^{+}\right)$548.2621, found 548.2624.

\section{N-( $N, N$-Dimethylaminomethylidenyl)-8-PRODAN-5'O-(4,4'-dimethoxytrityl)-2'-deoxyguanosine}

3'-O-(2-cyanoethyl)- $N, N$-diisopropylphosphoramidite (19). To a solution of 18 (30 mg, $0.054 \mathrm{mmol})$ in pyridine $(3 \mathrm{~mL})$ was added 4,4'-dimethoxytrityl chloride $(22 \mathrm{mg}, 0.064 \mathrm{mmol})$. The mixture was stirred at room temperature for $3 \mathrm{~h}$. The resulting mixture was evaporated and purified by silica gel column chromatography (chloroform-methanol $=50: 1)$ to yield the tritylated product $(45 \mathrm{mg}, 0.053$ mmol, 98\%) as a lemon yellow solid; ${ }^{1} \mathrm{H}$ NMR (DMSO-d $\left.6,400 \mathrm{MHz}\right) \delta 11.27$ (brs, $\left.1 \mathrm{H}\right), 8.50(\mathrm{~s}, 1 \mathrm{H})$, $8.37(\mathrm{~s}, 1 \mathrm{H}), 7.92(\mathrm{~d}, 1 \mathrm{H}, J=9.3 \mathrm{~Hz}), 7.84(\mathrm{dd}, 1 \mathrm{H}, J=1.5,8.3 \mathrm{~Hz}), 7.68(\mathrm{~d}, 1 \mathrm{H}, J=8.8 \mathrm{~Hz}), 7.30-7.12$ $(\mathrm{m}, 10 \mathrm{H}), 6.95(\mathrm{~d}, 1 \mathrm{H}, J=2.0 \mathrm{~Hz}), 6.75(\mathrm{dd}, 4 \mathrm{H}, J=8.8,12.2 \mathrm{~Hz}), 6.38(\mathrm{dd}, 1 \mathrm{H}, J=5.9,7.3 \mathrm{~Hz}), 5.37$ $(\mathrm{d}, 1 \mathrm{H}, J=4.4 \mathrm{~Hz}), 4.62-4.56(\mathrm{~m}, 1 \mathrm{H}), 3.89(\mathrm{dd}, 1 \mathrm{H}, J=5.4,8.8 \mathrm{~Hz}), 3.66(\mathrm{~s}, 3 \mathrm{H}), 3.65(\mathrm{~s}, 3 \mathrm{H})$, $3.72-3.52(\mathrm{~m}, 2 \mathrm{H}), 3.23-3.13(\mathrm{~m}, 4 \mathrm{H}), 3.06(\mathrm{~s}, 6 \mathrm{H}), 3.03(\mathrm{~s}, 3 \mathrm{H}), 3.00(\mathrm{~s}, 3 \mathrm{H}), 2.29-2.22(\mathrm{~m}, 1 \mathrm{H}) ;{ }^{13} \mathrm{C}$ NMR (DMSO-d $\left.d_{6}, 100 \mathrm{MHz}\right) \delta 197.3,158.0,157.9,157.5,157.2,156.2,150.3,150.2,148.9,144.9$, $137.3,135.64,135.58,130.7,129.9,129.6,129.5,127.6,126.5,125.9,124.6,123.9,118.4,116.4,113.0$, $104.8,85.2,85.1,82.7,79.2,70.4,63.6,54.9,40.7,37.9,34.6,34.4,22.0 ; \mathrm{FABMS}\left(\mathrm{NBA} / \mathrm{CHCl}_{3}\right) \mathrm{m} / \mathrm{z}$ 
$850\left([\mathrm{M}+\mathrm{H}]^{+}\right), \mathrm{HRMS}$ calcd. for $\mathrm{C}_{49} \mathrm{H}_{51} \mathrm{O}_{7} \mathrm{~N}_{7}\left([\mathrm{M}+\mathrm{H}]^{+}\right)$850.3928, found 850.3948.

To a solution of the tritylated nucleoside $(43 \mathrm{mg}, 51 \mu \mathrm{mol})$ and tetrazole $(3.5 \mathrm{mg}, 51 \mu \mathrm{mol})$ in anhydrous acetonitrile $(300 \mu \mathrm{L})$ and dichloromethane $(200 \mu \mathrm{L})$ was added 2-cyanoethyl tetraisopropylphosphorodiamidite $(15.8 \mu \mathrm{L}, 51 \mu \mathrm{mol})$ under nitrogen. The mixture was stirred at room temperature for $30 \mathrm{~min}$. The mixture was filtered and used with no further purification.

ODN synthesis and characterization. ODNs were synthesized by a conventional phosphoramidite method by using an Applied Biosystems 392 DNA/RNA synthesizer. Commercially available phosphoramidites were used for $\mathrm{dA}, \mathrm{dG}, \mathrm{dC}$, and $\mathrm{dT}$. The crude mixture after phosphoramidite synthesis was used for ${ }^{\text {PDN } X . ~ S y n t h e s i z e d ~ O D N s ~ w e r e ~ p u r i f i e d ~ b y ~ r e v e r s e ~ p h a s e ~ H P L C ~ o n ~ a ~ 5-O D S-H ~ c o l u m n ~(10 ~}$ $\times 150 \mathrm{~mm}$, elution with a solvent mixture of $0.1 \mathrm{M}$ triethylamine acetate (TEAA), pH 7.0, linear gradient over $30 \mathrm{~min}$ from $5 \%$ to $30 \%$ acetonitrile at a flow rate of $3.0 \mathrm{~mL} / \mathrm{min}$ ). ODNs containing modified nucleotides were fully digested with calf intestine alkaline phosphatase (50 U/mL), snake venom phosphodiesterase $(0.15 \mathrm{U} / \mathrm{mL})$, and $\mathrm{P} 1$ nuclease $(50 \mathrm{U} / \mathrm{mL})$ at $37^{\circ} \mathrm{C}$ for $3 \mathrm{~h}$. Digested solutions were analyzed by HPLC on a CHEMCOBOND 5-ODS-H column $(4.6 \times 150 \mathrm{~mm})$, elution with a solvent mixture of $0.1 \mathrm{M}$ TEAA, pH 7.0, flow rate of $1.0 \mathrm{~mL} / \mathrm{min}$. The concentration of each ODN was determined by comparing peak areas with a standard solution containing $\mathrm{dA}, \mathrm{dC}, \mathrm{dG}$, and $\mathrm{dT}$ at a concentration of 0.1 mM. MALDI-TOF ODN1( $\left.{ }^{\mathbf{P D N}} \mathbf{U}\right)$ : $\left([\mathrm{M}-\mathrm{H}]^{-}\right)$calcd. 4098.81, found 4098.23. ODN2( $\left.{ }^{\mathbf{P D N}} \mathbf{U}\right):\left([\mathrm{M}-\mathrm{H}]^{-}\right)$calcd. 4128.83, found 4129.04. ODN1 $\left({ }^{\mathbf{P D N}} \mathbf{C}\right):\left([\mathrm{M}-\mathrm{H}]^{-}\right)$calcd. 4097.83, found 4097.97. ODN1( $\left.{ }^{\mathbf{P D N}} \mathbf{A}\right):\left([\mathrm{M}-\mathrm{H}]^{-}\right)$calcd. 4121.85, found 4121.57. ODN1( $\left.{ }^{\mathbf{P D N}} \mathbf{G}\right):\left([\mathrm{M}-\mathrm{H}]^{-}\right)$ calcd. 4137.85 , found 4137.95 . 


\section{Scheme S1 ${ }^{a}$}
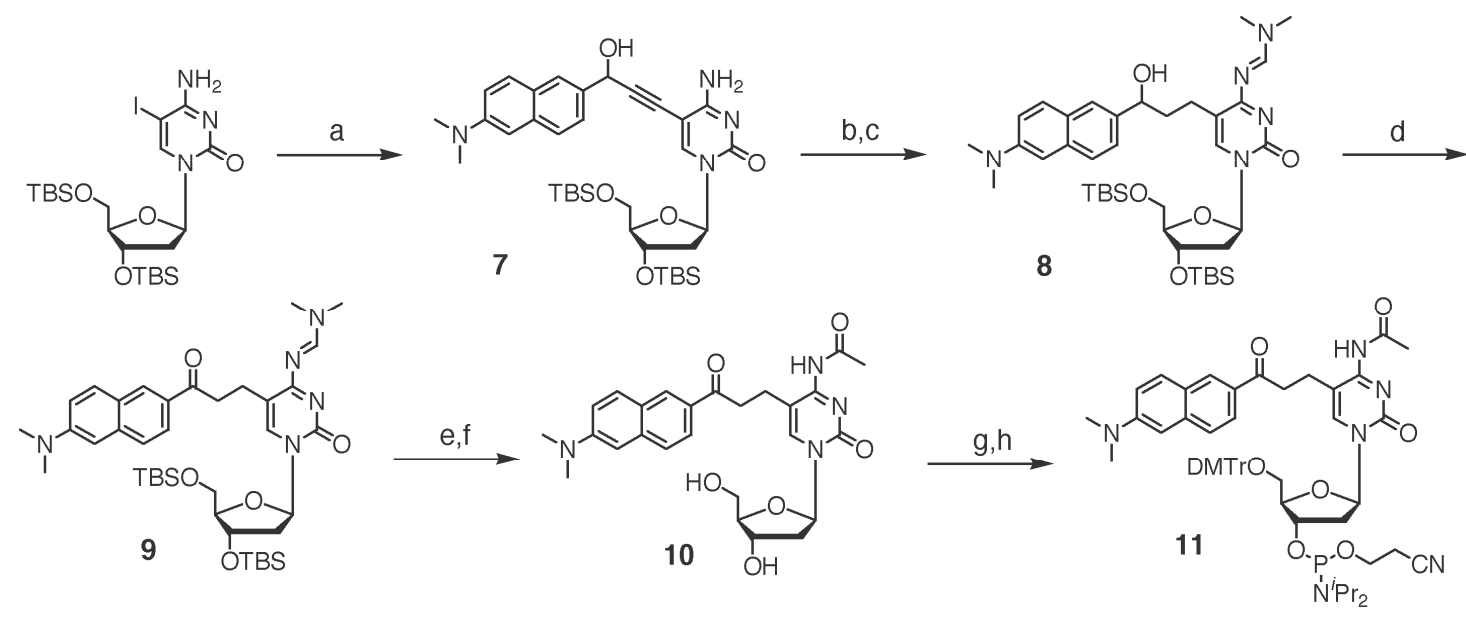

a Reagents and conditions: (a) 2, tetrakis(triphenylphosphine)palladium(0), copper(I) iodide, triethylamine, DMF, room temperature, $3 \mathrm{~h}, 92 \%$; (b) $10 \% \mathrm{Pd} / \mathrm{C}$, ethanol, $\mathrm{H}_{2}$, room temperature, $9 \mathrm{~h}$, $80 \%$; (c) $N, N$-dimethylformamide dimethylacetal, DMF, $60{ }^{\circ} \mathrm{C}, 3 \mathrm{~h}, 81 \%$; (d) tetrapropylammonium perruthenate, 4-methylmorpholine $\mathrm{N}$-oxide, $4 \AA \mathrm{MS}$, dichloromethane, room temperature, $4 \mathrm{~h}, 72 \%$; (e) conc. ammonia-methanol (1:4), $50{ }^{\circ} \mathrm{C}, 2 \mathrm{~h}$, then anhydrous acetic acid, pyridine, $50{ }^{\circ} \mathrm{C}, 4 \mathrm{~h}, 85 \%$; (f) 1 M tetrabutylammonium fluoride, room temperature, 3 h, 96\%; (g) 4,4'-dimethoxytrityl chloride, pyridine, room temperature, $3 \mathrm{~h}, 90 \%$; (h) $\left(\mathrm{iPr}_{2} \mathrm{~N}\right)_{2} \mathrm{PO}\left(\mathrm{CH}_{2}\right)_{2} \mathrm{CN}, 1 H$-tetrazole, acetonitrile, room temperature, $30 \mathrm{~min}$. 
Scheme S2 ${ }^{a}$
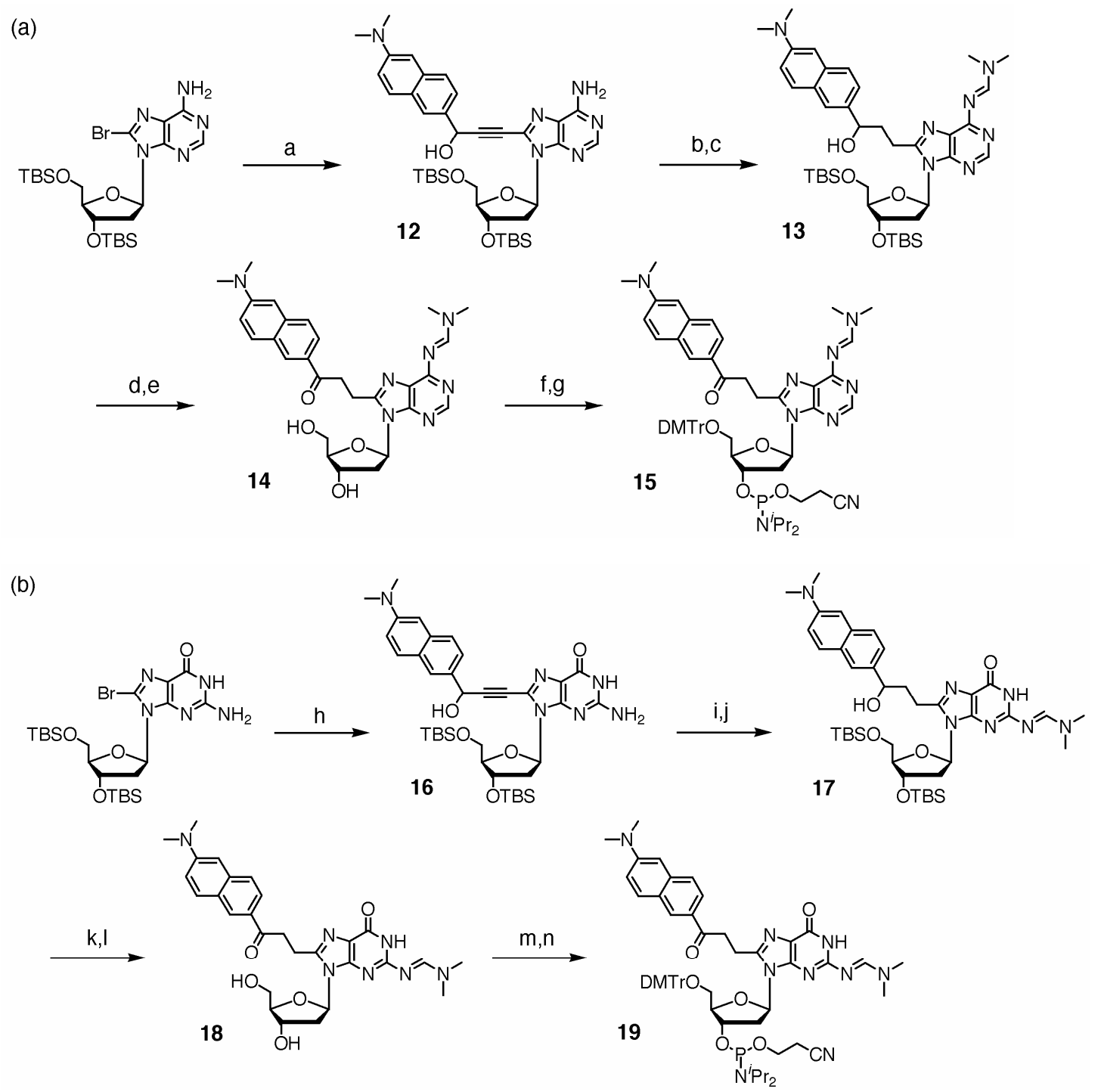

a Reagents and conditions: (a) 2, tetrakis(triphenylphosphine)palladium(0), copper(I) iodide, triethylamine, DMF, room temperature, $17 \mathrm{~h}, 61 \%$; (b) $5 \% \mathrm{Pd} / \mathrm{C}$, methanol, $\mathrm{H}_{2}$, room temperature, 2 days, 45\%; (c) N,N-dimethylformamide dimethylacetal, DMF, room temperature, $6 \mathrm{~h}, 75 \%$; (d) tetrapropylammonium perruthenate, 4-methylmorpholine $N$-oxide, $4 \AA \mathrm{MS}$, dichloromethane, room temperature, $15 \mathrm{~h}, 32 \%$; (f) $1 \mathrm{M}$ tetrabutylammonium fluoride, room temperature, $3 \mathrm{~h}, 92 \%$; (g) 4,4'-dimethoxytrityl chloride, pyridine, room temperature, $3 \mathrm{~h}, 49 \%$; (h) $\left(i \mathrm{Pr}_{2} \mathrm{~N}\right)_{2} \mathrm{PO}\left(\mathrm{CH}_{2}\right)_{2} \mathrm{CN}$, $1 \mathrm{H}$-tetrazole, acetonitrile, room temperature, $30 \mathrm{~min}$; (h) 2, tetrakis(triphenylphosphine)palladium(0), copper(I) iodide, triethylamine, DMF, $60{ }^{\circ} \mathrm{C}, 1 \mathrm{~h}, 93 \%$; (i) $\mathrm{PtO}_{2}$, methanol, $\mathrm{H}_{2}$, room temperature, $12 \mathrm{~h}$, $68 \%$; (j) $\mathrm{N}, \mathrm{N}$-dimethylformamide dimethylacetal, DMF, $60{ }^{\circ} \mathrm{C}, 1 \mathrm{~h}, 76 \%$; (k) tetrapropylammonium perruthenate, 4-methylmorpholine $N$-oxide, $4 \AA$ MS, dichloromethane, room temperature, $2 \mathrm{~h}, 72 \%$; (l) $1 \mathrm{M}$ tetrabutylammonium fluoride, room temperature $2 \mathrm{~h}, 94 \%$; (m) 4,4'-dimethoxytrityl chloride, pyridine, room temperature, $3 \mathrm{~h}, 98 \%$; (n) $\left(\mathrm{iPr}_{2} \mathrm{~N}\right)_{2} \mathrm{PO}\left(\mathrm{CH}_{2}\right)_{2} \mathrm{CN}, 1 \mathrm{H}$-tetrazole, acetonitrile, room temperature, $30 \mathrm{~min}$. 